\title{
RESIDÊNCIA PROFISSIONAL E ASSISTÊNCIA TÉCNICA NO BAIRRO PESTANO - PELOTAS/RS
}

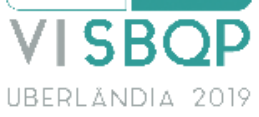

\author{
SANTOS, Luísa de Azevedo dos \\ PROGRAU - FAURB - Universidade Federal de Pelotas, e-mail: luisaxavante@gmail.com \\ TAVARES, Bruna Bergamashi \\ PROGRAU - FAURB - Universidade Federal de Pelotas, e-mail: bruna.bt09@gmail.com \\ MEDVEDOVSKI, Nirce Saffer \\ PROGRAU - FAURB - Universidade Federal de Pelotas, e-mail: nirce.sul@gmail.com
}

\begin{abstract}
RESUMO
O presente artigo aborda o processo de desenvolvimento de assistência técnica junto à comunidade do bairro Pestano, na cidade de Pelotas/RS. Será apresentada a área do bairro, com sua localização territorial, histórico e alguns dados sociais. Sobre a aplicação do trabalho de assistência técnica fica relatada a proposta coletiva, fruto do curso da especialização em Assistência Técnica para Habitação Social e Direito à Cidade, desenvolvida em parceria pelos programas de Pós Graduação em Arquitetura e Urbanismo da Universidade Federal da Bahia e da Universidade Federal de Pelotas. Destaca-se o caráter inovador das metodologias e estrutura adotada para o trabalho em conjunto com os moradores da comunidade. Por fim, são apresentado os projetos de autoria das arquitetas residentes, juntamente com uma análise sobre o processo e seus possíveis desdobramentos.
\end{abstract}

Palavras-chave: Pestano. Assistência técnica, Residência em Arquitetura e Urbanismo. Metodologias participativas de projeto.

\begin{abstract}
This article discusses the process of developing technical assistance to the community of Pestano neighborhood, in the city of Pelotas / RS. The area of the neighborhood will be presented, with its territorial location, history and some social data. Regarding the application of the technical assistance work, the collective proposal is reported as a result of the specialization course in Technical Assistance for Social Housing and Right to the City, developed in partnership by the Graduate Programs in Architecture and Urbanism of the Federal University of Bahia and the Federal University of Pelotas. It highlights the innovative nature of the methodologies and structure adopted for working together with the residents of the community. Finally, it presents the projects authored by resident architects, along with an analysis of the process and its possible developments.
\end{abstract}

Keywords: Pestano. Technical assistance, Residency in Architecture and Urbanism. Participatory project methodologies.

\section{INTRODUÇÃO}

A Residência em Arquitetura e Urbanismo e Engenharia da Universidade Federal da Bahia (RAU+E) tem sua proposta embasada na Lei № 11.888/2008, a qual prevê em seu art. $4^{\circ}$, inciso III, a prestação de serviços através da assistência técnica por "profissionais inscritos em programas de residência acadêmica em arquitetura, urbanismo ou engenharia ou em programas de extensão universitária, por meio de escritórios-modelos ou escritórios públicos com atuação na área". Esta lei, conforme seu artigo primeiro, "assegura o

SANTOS, L. A.; TAVARES, B. B.; MEDVEDOVSKI, N. S. Residência profissional e assistência técnica no bairro Pestano - Pelotas/RS. In: SIMPÓSIO BRASILEIRO DE QUALIDADE DO PROJETO NO AMBIENTE CONSTRUÍDO, 6., 2019, Uberlândia. Anais... Uberlândia: PPGAU/FAUeD/UFU, 2019. p. 353-364. DOI https://doi.org/10.14393/sbqp19034. 
direito das famílias de baixa renda à assistência técnica pública e gratuita para o projeto e a construção de habitação de interesse social, como parte integrante do direito social à moradia previsto no art. $6^{\circ}$ da Constituição Federal". Dessa forma ela abre a possibilidade da prestação de serviço dos profissionais de arquitetura e urbanismo e de engenharia para desenvolver projetos para e com a população em vulnerabilidade social. Procura ativar a função social dessas profissões, tão necessárias em um país como o Brasil, com um contexto em que a exclusão social não é passível de mensuração e está caracterizada pela informalidade, irregularidade, ilegalidade, pobreza, baixa escolaridade e a ausência de cidadania. (MARICATO, 1996).

Nesse sentido, o artigo apresentará o trabalho desenvolvido pelas arquitetas residentes da terceira turma da RAU+E e seus orientadores, em nucleação com a Faculdade de Arquitetura e Urbanismo da Universidade Federal de Pelotas, junto ao grupo de moradores do bairro Pestano, na cidade de Pelotas/RS.'

\section{CARACTERIZAÇÃo DA ÁREA}

O bairro Pestano está localizado na região administrativa das Três Vendas (TV, demarcação em laranja), uma das sete macrorregiões conforme o III Plano Diretor de Pelotas (Figura 1). Com o crescimento de Pelotas, indústrias e comércios foram instalados em uma das entradas da cidade, na região que atualmente é conhecida como Três Vendas. Ao longo do século XX a região começou a se consolidar com a formação de pequenas vilas, sendo que as vilas do Pestano demarcada em vermelho no mapa abaixo (Figura 1) e Getúlio Vargas, limítrofe ao Pestano, começam a se desenvolver a partir dos anos de 1970 em terras públicas. No ano de 1977 ocorreu uma enchente na cidade e no ano de 1978 a prefeitura iniciou o parcelamento do solo de um terreno de sua posse, onde hoje se localiza o Pestano. Grande parte dessas famílias que ficaram desabrigadas pela enchente foram levadas para lá e, progressivamente, o local passou a receber a população de baixa renda e/ou sem moradia, da cidade e ainda famílias provenientes do êxodo rural, principalmente do interior de cidades próximas ao município.

A partir de sua formação histórica, pode-se observar que os bairros Pestano e Getúlio Vargas possuem uma origem similar a muitos contextos periféricos das cidades brasileiras. No entanto, ao longo do desenvolvimento do trabalho, tornou-se evidente a necessidade de compreensão de alguns fatores específicos da constituição das periferias em cidades médias, como é o caso de Pelotas, sendo que a convivência, na periferia de pelotas, entre especulação imobiliária e urbanização precária, passou a fazer parte do seu cotidiano (CARRASCO, 2017, p. 608).

Com base em dados fornecidos pela prefeitura municipal de Pelotas, pelo projeto da empresa contratada, no ano de 2013 a população no Pestano era de 3.659 habitantes com uma área de $460.107 .55 \mathrm{~m}^{2}$ e 1237 lotes e está localizado a aproximadamente $8 \mathrm{~km}$ do centro da cidade (CE). É nesse

\footnotetext{
I A nucleação da Residência em Arquitetura e Urbanismo e Engenharia da Universidade Federal da Bahia (RAU+E) com a Faculdade de Arquitetura e Urbanismo da UFPel foi estabelecida no ano de 2018, com as coordenações, respectivamente, das professoras Angela Gordilho e Nirce Saffer Medvedovski, e participação dos professores Eduardo Rocha e André Carrasco como orientadores.
} 
território e universo populacional que se inicia a proposta para assistência técnica da Residência da Nucleação de Pelotas.

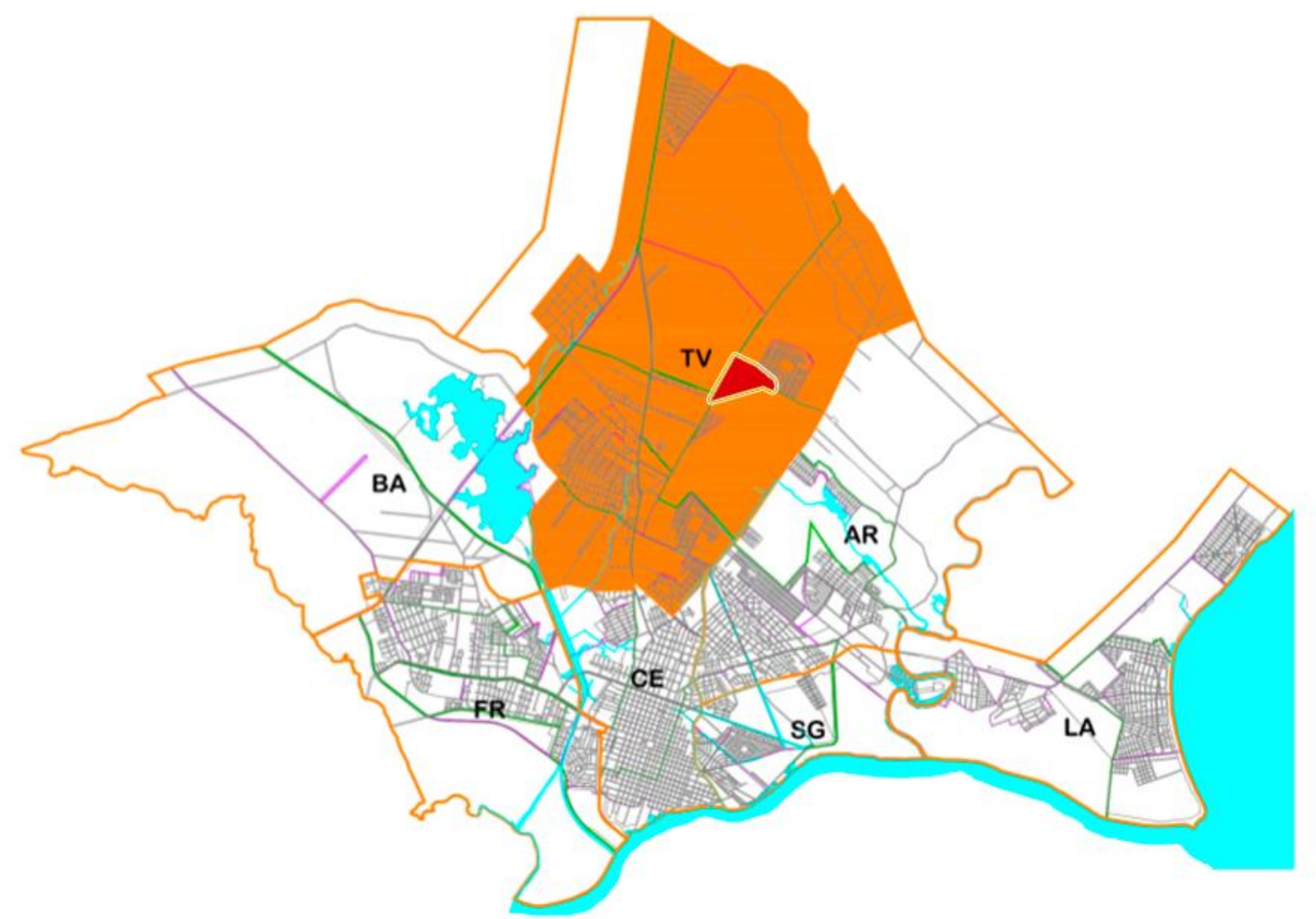

Figura 1 - Mapa Urbano Pelotas/RS - Regiōes Administrativas - Inserção Bairro Pestano Fonte: Redesenho sobre Mapa Urbano - Equipe RAU+ E Pestano (2018)

\section{PROPOSTA COLETIVA DE ASSISTÊNCIA TÉCNICA}

Entendendo que as relações entre indivíduos e os espaços que estes habitam são de extrema importância para questões de pertencimento e apropriação, um dos fios condutores deste trabalho se embasa nos conceitos do Direito à Cidade, considerando as teorias de Henri Lefebvre (2001).

Para o processo de escolha do local de trabalho e de aproximação com a comunidade priorizou-se um desenvolvimento que pudesse ativar a busca por esse direito em algum local emergente da cidade. Dessa forma, essa busca se iniciou através do contato com a Prefeitura Municipal de Pelotas, procurando um diálogo com os órgãos públicos municipais que direcionasse a um local com potencial de aplicabilidade de um projeto de assistência técnica em AU\&E. Assim, surgiu a indicação dos bairros Pestano e Getúlio Vargas. Ambos se encontram em situação irregular, em estado de urbanização precária consolidada e estão contemplados por um projeto de Qualificação Física e Social da Prefeitura Municipal, contratado a uma empresa privada, o qual abrange a regularização fundiária, projeto de equipamentos comunitários e áreas verdes, além de projetos de infraestrutura urbana.

Para a definição do campo de trabalho foi importante considerar que o universo que abrange o Projeto de Qualificação (Pestano e Getúlio Vargas) era muito amplo, sendo então selecionado somente o Pestano para a atuação pelas residentes. A escolha se deu, pois o processo de regularização 
fundiário foi iniciado pelo Pestano, decisão feita pela Secretaria de Habitação e Regularização Fundiária.

Em março de 2018 foi marcado o primeiro encontro, no salão da comunidade católica Cristo Salvador para apresentar de forma mais aprofundada a proposta de trabalho a ser desenvolvida. Nessa reunião foram apresentadas algumas possibilidades de abordagem de trabalhos;

\section{METODOLOGIAS PARA PRÁTICA COLETIVA DE ASSISTÊNCIA TÉCNICA}

O trabalho desenvolvido teve como princípios a construção de processo para a assistência técnica embasada em processo participativo através de metodologias integrativas. Para tanto, aplicaram-se algumas dinâmicas ao longo dos encontros e oficinas com a comunidade com o intuito de promover a aproximação, conhecimento e diálogo com a mesma. Estas dinâmicas fizeram parte da formação das arquitetas durante o período de capacitação presencial no programa RAU+E.

O processo de trabalho foi feito através da estruturação de três eixos temáticos, que foram discutidos e acordados com o grupo de moradores que acompanharam o processo. Foram definidos os seguintes eixos:

1) Eixo memória e identidade, eixo proposto pelos moradores, que resgatasse a origem e história do lugar;

2) Eixo projeto, obra e pós-obra, uma unificação de dois eixos propostos, com perspectiva de apropriar os moradores do projeto de Qualificação;

3) Eixo socioambiental, mantendo a importância da abordagem referente ao descarte de resíduos e ainda problemas relativos a áreas alagadiças.

Considerando a base teórica desenvolvida na primeira etapa da RAU+E, adotou-se como premissa a utilização das técnicas de metodologias integrativas para processos participativos, tendo como referência para a formulação da metodologia aplicada no processo específico o "espiral da assistência técnica" (Mettig-Rocha e Moura, 2016), com o desenvolvimento das etapas de encontro, levantamento de necessidades, sonhar juntos e projetação. Cada eixo foi desenvolvido dentro de uma média de três encontros, os quais foram previamente estruturados e pensados a partir das dinâmicas integrativas para serem abordados.

O eixo memória e identidade, teve entre suas estruturas de desenvolvimento a dinâmica de "contação de história", onde foi proposto que os moradores trouxessem, de modo oral, algumas lembranças marcantes da sua história no bairro. Essa dinâmica teve como objetivo resgatar memórias individuais e coletivas que se relacionam com a história do bairro. A partir dessa atividade, desdobraram-se duas propostas: (a) a criação de um canal de comunicação e informativo para os moradores do Pestano; (b) criação de uma identidade visual que representasse o espírito comunitário do local e que servisse de logo ao projeto em desenvolvimento.

Para o encaminhamento das propostas, as ações executadas foram a criação de um perfil na rede social Facebook. Também houve a escolha de um nome para o perfil, batizado como "Eu amo o Pestano". 
Para a criação da identidade visual foi realizado um processo criativo junto aos moradores. A dinâmica buscou identificar símbolos e cores para a concepção desse símbolo.

O segundo eixo foi o de projeto, obra e pós-obra. A base de desenvolvimento se deu em discussões a respeito da importância da arquitetura e urbanismo desde sua aplicação na pequena escala da habitação até o planejamento urbano das cidades. A proposta principal foi a de promover a aproximação do trabalho do arquiteto e urbanista com essa população que não tem acesso a esse serviço. Foram feitas oficinas para compreensão da importância do projeto, leitura de desenhos técnicos, discussão sobre a lei de Assistência Técnica e o direito à cidade. Esse último assunto foi abordado através de um jogo de perguntas e respostas que levavam à reflexão sobre o acesso dos moradores do Pestano ao direito à cidade.

Também foi promovida uma apresentação aprofundada do Projeto de Qualificação Física e Social. Para isso foi montada uma maquete com a identificação das estruturas e onde elas seriam construídas, além da demonstração do caderno de desenhos técnicos do projeto.

Dentro desse contexto, foi discutida as etapas de obra e seus transtornos e cuidados. A conscientização sobre o pós-obra, as mudanças no ambiente e a necessidade de manutenção e zelo, também foram pautadas.

O terceiro e último eixo, abordando o tema socioambiental, foi trabalhado de forma instrutiva e informativa. Sua abordagem foi através da apresentação da estrutura de coleta de lixo da cidade de Pelotas, focando nas formas de coleta, serviços de ecoponto, cooperativas de reciclagem e descarte consciente dos resíduos sólidos.

Além da estruturação dos encontros, foi promovida a aplicação do DRUP Diagnóstico Rápido Urbano Participativo. O DRUP envolve uma nova abordagem sobre as comunidades em que o agente de desenvolvimento vai aprender da comunidade local. Isso significa, estar com a população local, escutá-la, dialogar e juntos tentar solucionar os problemas." (MEDVEDOVSKI, 2015).
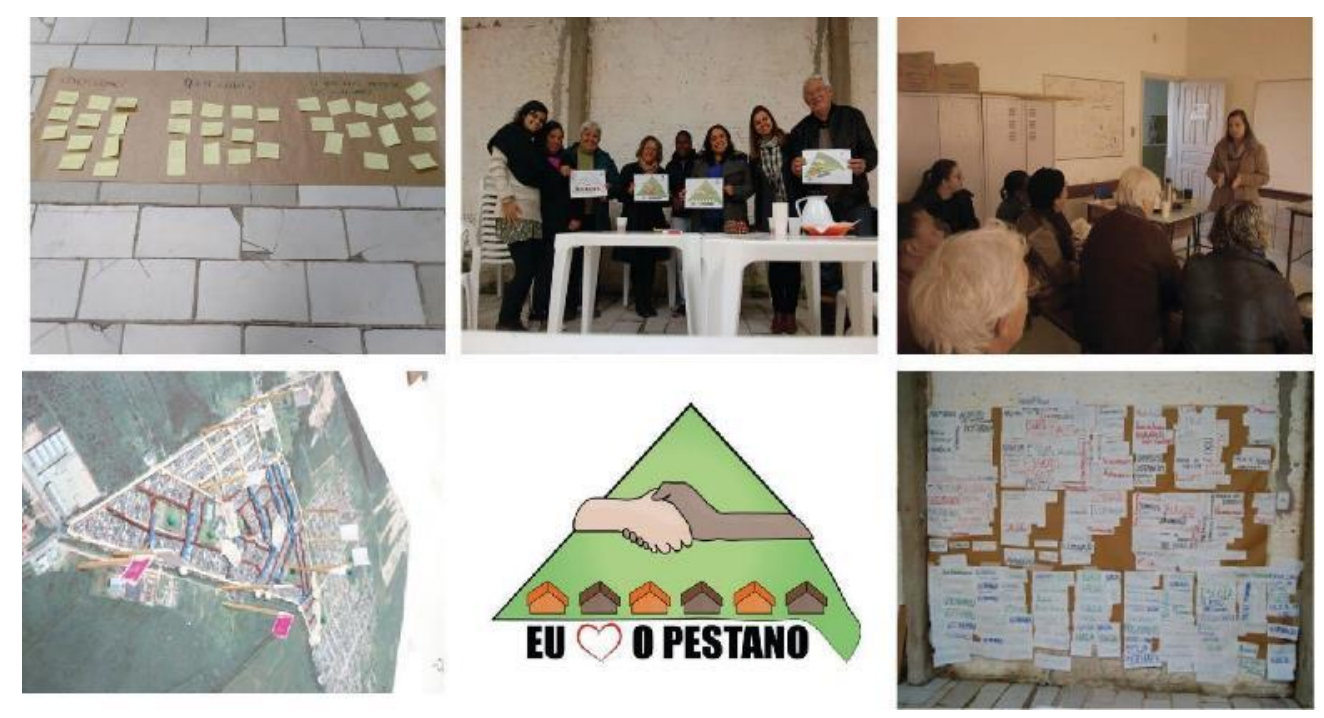

Figura 2 - Fotos das oficinas e encontros no bairro Pestano

Fonte: Acervo equipe RAU+E Pestano 


\section{DEFINIÇÃO DE PROJETOS ESPECÍFICOS}

Os resultados para as definições dos projetos surgiram ao longo do andamento de cada eixo. Esses resultados originaram-se de algumas insuficiências do projeto de Qualificação Física e Social proposto e terceirizado pela prefeitura, as quais foram detectadas durante o desenvolvimento do eixo 2, juntamente com as problemáticas abordadas durante o eixo 3, o qual abrangeu de forma mais específica a questão da gestão dos resíduos sólidos no loteamento.

Dentro do eixo projeto, obra e pós-obra, analisou-se de forma mais aprofundada junto aos moradores os projetos de qualificação urbana para o Pestano e Getúlio Vargas e observou-se que as vias de acesso, configuradas pela Av. Zeferino Costa e pela Av. Leopoldo Brod não estavam contempladas com ajustes e melhorias de infraestrutura. Além disso, as franjas opostas ao polígono interno ao loteamento também não receberiam o tratamento de passeio público.

No eixo socioambiental, foi realizado junto ao grupo um mapeamento dos pontos críticos de acúmulo de lixo gerados pelo incorreto manuseio desse material pelos próprios moradores e ainda foi analisado e constatado a falta de um ecoponto na região das três vendas, junto ao interesse da população do Pestano e a disponibilidade de terras públicas no entorno do perímetro do bairro.

Outro ponto observado foi a importância de realizar um registro ilustrativo sobre o processo de desenvolvimento dos eixos que pudesse servir como um meio informativo para a comunidade do Pestano, em especial para a grande parcela da população que não entrou em contato com essa construção, e também como resultado do trabalho de assistência técnica efetivado pelas residentes. Assim, ficou estabelecida a criação de uma cartilha sobre os assuntos abordados nos três eixos de trabalho, intitulada: "Cartilhas Informativas Pestano".

Com essas três propostas de projeto delineadas, foram definidas coletivamente quais seriam as diretrizes e programas para cada um deles; Foi feita a divisão entre a equipe da responsabilidade técnica de cada um, onde a residente arquiteta Luísa Santos realizou o projeto do ecoponto e das cartilhas informativas e a arquiteta residente Bruna Tavares realizou o projeto de requalificação das vias de acesso do bairro Pestano.

\subsection{Projeto de requalificação das vias de acesso do bairro Pestano}

O projeto de requalificação urbana das vias de acesso do bairro Pestano foi desenvolvido nos trechos das avenidas Zeferino Costa e Leopoldo Brod, as quais configuram o limite do perímetro do bairro Pestano.

Os objetivos do projeto se propõem a promover o exercício da assistência técnica, estimular práticas participativas e coletivas para desenvolvimento de projeto, promover o direito à cidade através da qualificação urbana dos espaços, promover a preservação ambiental e as relações humanas com o meio ambiente, promover condições de mobilidade adequadas e estimular a apropriação coletiva dos espaços com qualidade urbana.

Os principais problemas detectados em relação a avenida Zeferino Costa envolvem: a recuperação e melhoria da condição viária e urbana, o acúmulo 
de lixo no lado oposto ao bairro Pestano mostrou-se como possível consequência da falta de infraestrutura urbana, o depósito de lixo nesses locais é feito, em sua maioria, pelos próprios moradores do bairro e tem como principais pontos as saídas das ruas internas do bairro.

O projeto para essa avenida se define com a proposta da configuração de um passeio público com desenho de canteiro e inserção de mobiliários urbanos e iluminação. Além da reconfiguração da caixa da rua, em especial sua dimensão e a falta de sinalização de trânsito. Foi projetada 3 pistas em cada sentido divididas por canteiro central e com definição adequada de faixa de pedestres (Figura 3). O projeto define a caixa máxima da avenida em $40 \mathrm{~m}$, com base no III Plano Diretor.

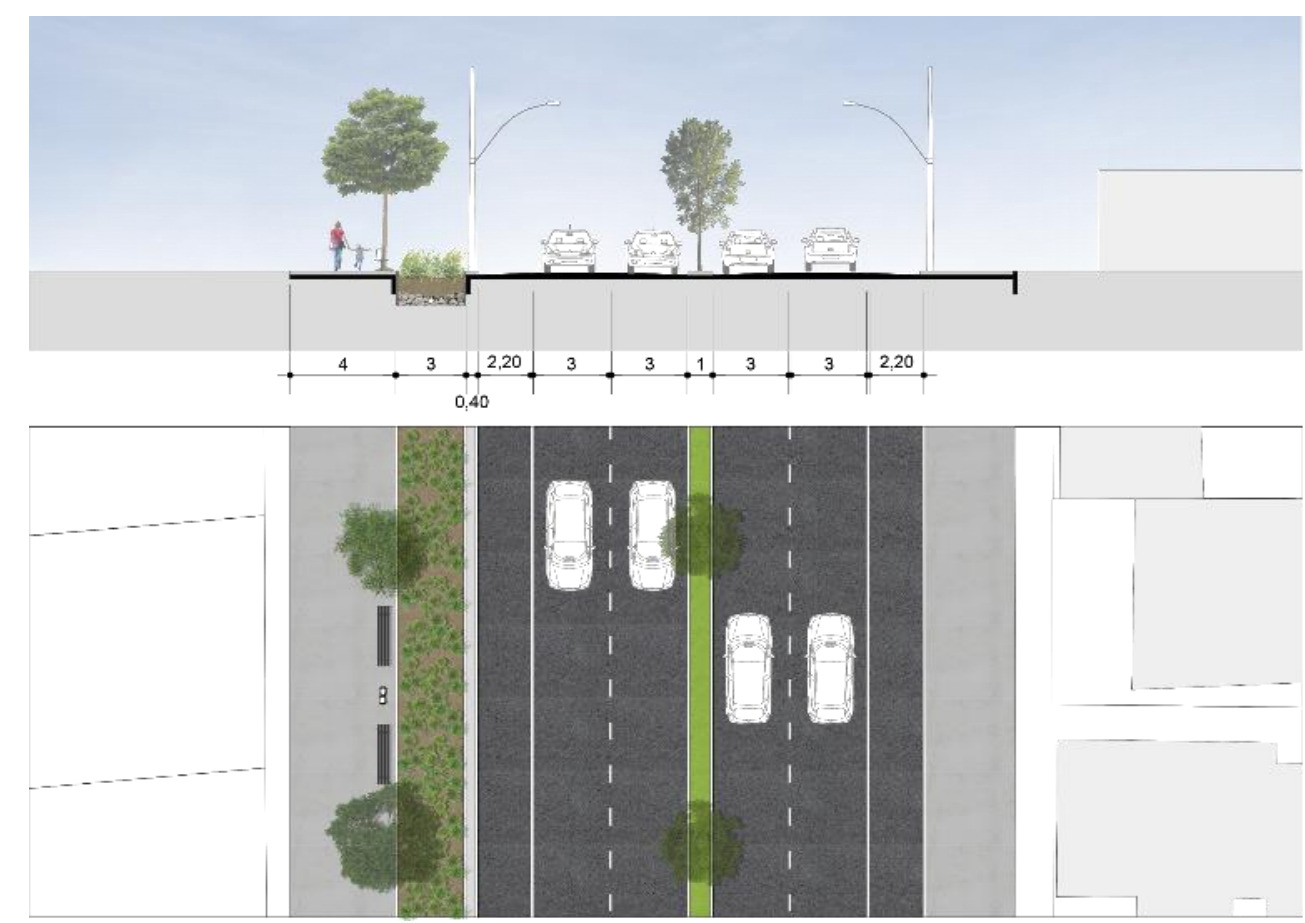

Figura 3 - Imagem do perfil viário da avenida Zeferino Costa do projeto de requalificação urbana das vias de acesso do bairro Pestano

Fonte: Arq. Bruna Bergamaschi Tavares (2018)

A avenida Leopoldo Brod tem como principal problemática a condição viária e de acesso ao colégio Francisco Carrucio (CAIC), o qual é separado da via principal por um canal e tem interface direta com uma rua secundária em condições precárias.

Foi redesenhada a caixa da avenida e da rua secundária. $\bigcirc$ projeto inclui o desenho de ciclovia (prevista no III Plano Diretor), travessias elevadas para pedestres, passeio público com pontos de travessia peatonal e de carro junto ao canal. Esses pontos de travessia se conectam avenida Leopoldo Brod a rua secundária, a qual promove o acesso ao colégio e aos terrenos vizinhos ao mesmo (Figura 4). Nesses terrenos encontra-se como uso uma pequena ocupação de moradia, a qual tem novo acesso configurado, e uma área de terreno municipal, onde foi feito o redesenho de um campo de futebol inativo atualmente. Junto disso foi proposto um parque recreativo, a fim de 
complementar o uso do campo de futebol. Também foi definido nessa área a implantação do projeto do Ecoponto do bairro Pestano, com projeto de autoria da arquiteta Luisa dos Santos.
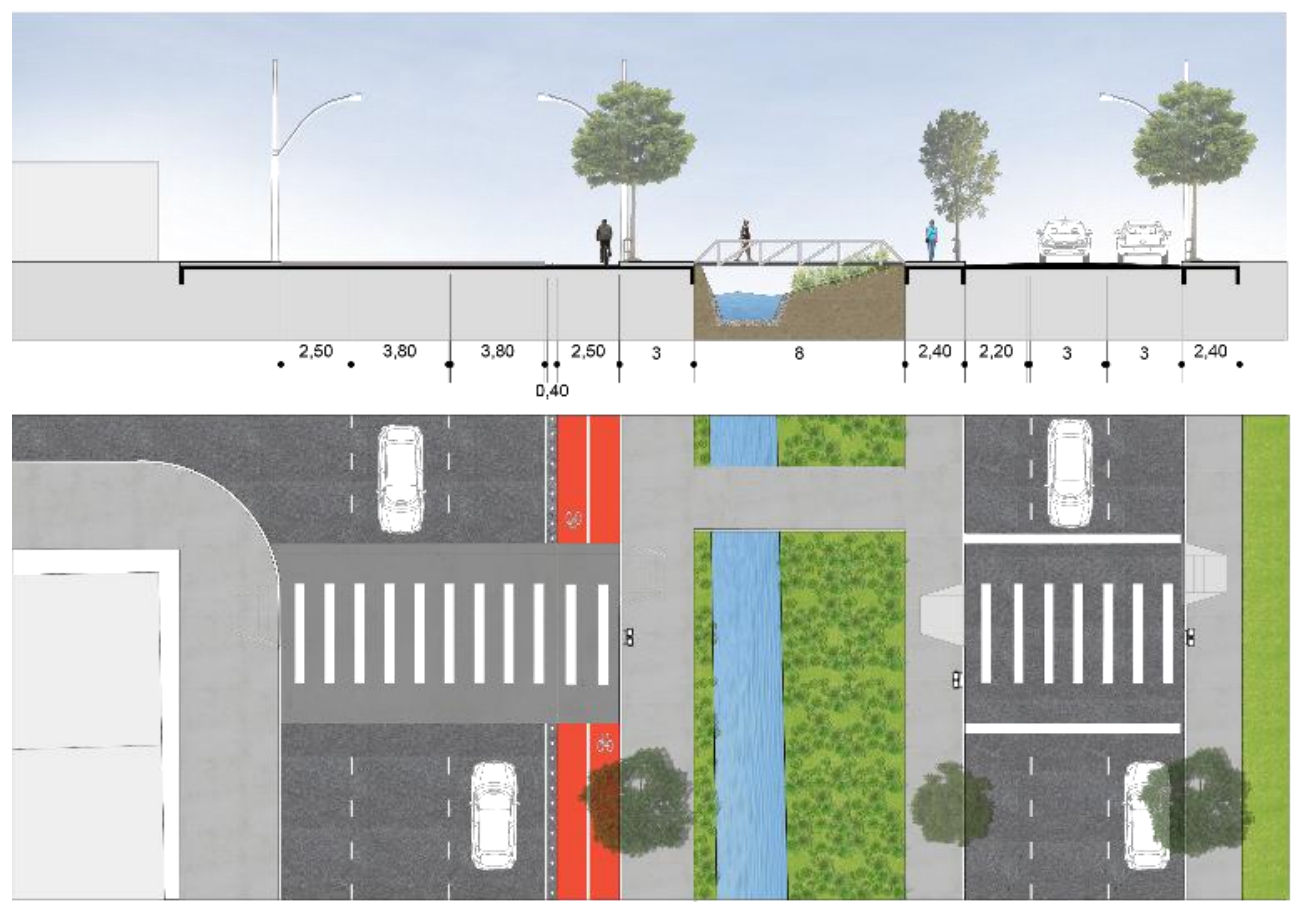

Figura 4 - Imagem do perfil viário da avenida Leopoldo Brod do projeto de requalificação urbana das vias de acesso do bairro Pestano

Fonte: Arq. Bruna Bergamaschi Tavares (2018)

\subsection{Projeto do ecoponto Pestano}

Na definição do programa de necessidades do Ecoponto foram levadas em consideração questões levantadas pelos moradores e questões técnicas, como: a ampliação dos tipos de descarte em ecopontos na cidade de Pelotas, levantamento e pesquisa de campo sobre tipos de ecopontos existentes no Brasil e seus formatos, quais materiais são aceitos para descarte, assim como a forma de armazenamento, de descarte e manuseio e quais as prioridades para a instalação de um equipamento público deste tipo no município de Pelotas/RS conforme a Secretaria de Serviços Urbanos.

Foi possível propor o equipamento e a ampliação de tipos de descarte, suprindo as considerações levantadas pelos moradores, chegando a um programa que contempla: 1. Container Administrativo, com escritório e banheiro; 2. Container Educativo de Descarte, para orientação de descarte de material reciclável (papel, plástico, metal e vidro); 3. Espaço Educativo, local para palestras, oficinas e eventos relacionados a reciclagem e preservação do meio ambiente; 4. Container para as Cooperativas, local para armazenamento dos recicláveis que serão enviados para as cooperativas cadastradas, exceto vidros que ficam armazenados nas coletoras grandes devido ao peso e facilidade de transporte; 5. Container de Resíduos A, para descarte de lâmpadas fluorescentes, pilhas e baterias, remédios vencidos e eletroeletrônicos; 6. Espaço de Resíduos B, para descarte de pneus, óleo de cozinha usado e eletrodomésticos de grande porte; 7. Plataforma de descarte, 
para o descarte de restos de podas e jardinagem, resíduos da construção civil, madeira, móveis desmontados e vidros das cooperativas e 8. Container de Materiais, para armazenamento de materiais descartados que estão em bom estado de conservação e que podem ser destinados ao banco de materiais e doados a famílias que precisam construir, ampliar ou reformar sua habitação.

Com o programa pronto, foi verificado o local para implantação do mesmo, nas terras públicas disponíveis, e organizada a logística interna para 0 zoneamento e a implantação do mesmo, chegando ao um anteprojeto que concentra mais tipos de descartes em um único ponto, facilitando a logística dos moradores. O ecoponto acabará auxiliando na problemática do descarte incorreto de resíduos do bairro e seu entorno, demanda relatada pelos usuários e projetada e estruturada de forma coletiva.

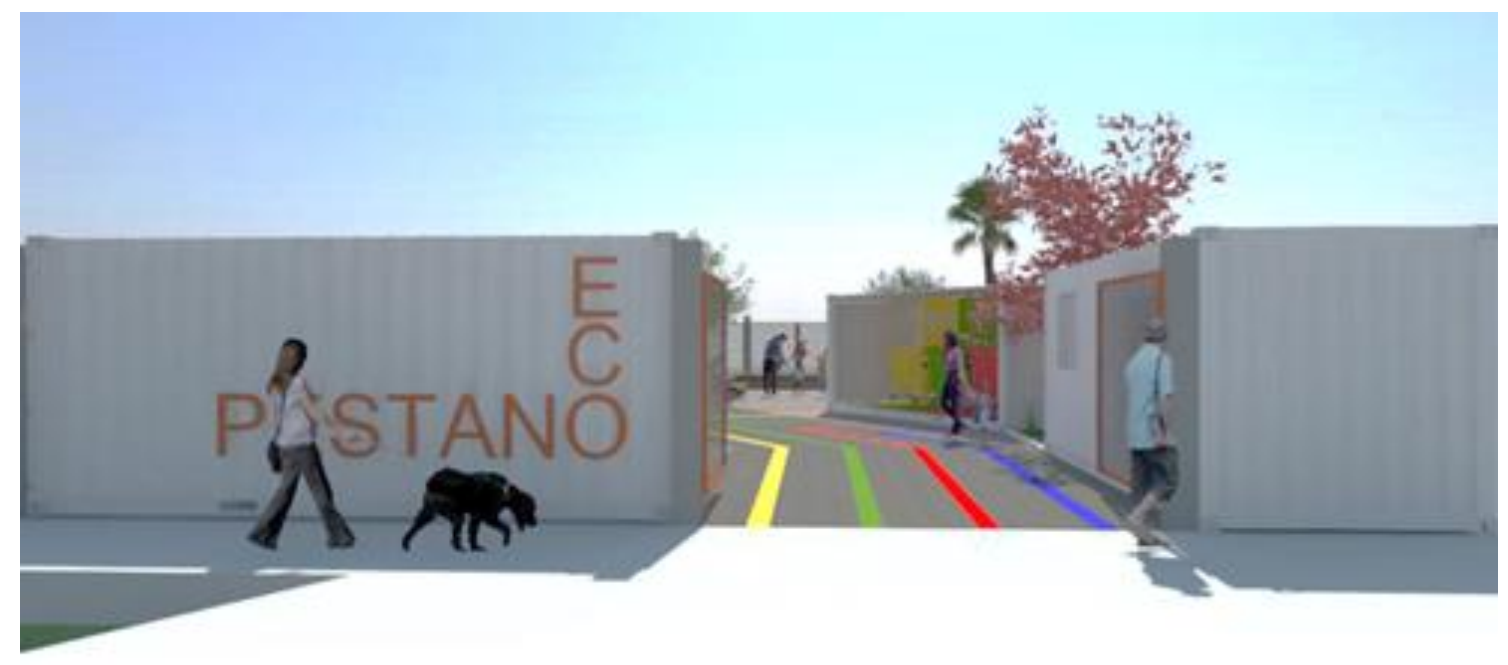

Figura 5 - Projeto ecoponto Pestano - acesso principal Fonte: Arq. Luísa de Azevedo dos Santos (2018)

\subsection{Projeto das Cartilhas Informativas Pestano}

Para o projeto das cartilhas informativas, foi levado em consideração todo o processo realizado ao longo dos encontros e dos três eixos de trabalho, sendo então realizadas três cartilhas, uma para cada eixo, denominadas: Cartilha Informativa Identidade e Memória, Cartilha Informativa Projeto|Obra|Pós Obra e Cartilha Informativa Socioambiental.

Nas cartilhas foram apresentados textos sucintos e estruturados desenhos e esquemas sobre os temas abordados durante os encontros, com intuito de facilitar a compreensão e leitura do conteúdo (Figura 6). As cartilhas são importantes para o registro do processo de assistência técnica realizado no bairro, documentando tudo que foi debatido e construído nesse período e também como forma de dissipar esse conhecimento aos demais moradores do Pestano, que acabaram não participando do processo durante o ano de 2018, mas que poderão ter acesso a tal conteúdo, prolongando essa assistência e repassando o conhecimento. 


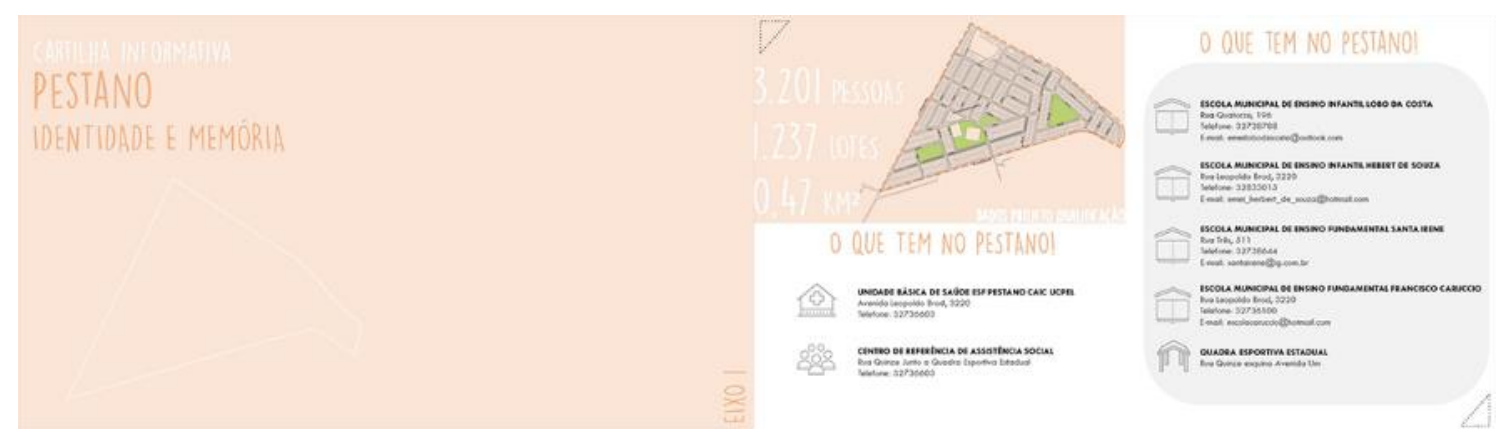

Figura 6 - Cartilha Informativa Eixo Identidade e Memória (capa e pág. 5 e 6)

Fonte: Arq. Luísa de Azevedo dos Santos (2018)

\section{CONCLUSÕES E ENCAMINHAMENTOS}

É importante salientar que o processo da residência e a efetivação da assistência técnica promove uma experiência singular para os envolvidos no processo e acaba promovendo a difusão da prática profissional do arquiteto e urbanista nesta área de atuação, necessária tanto para o profissional quanto para o beneficiário, compreendendo o sentido e colocando em prática a lei de assistência técnica.

Os projetos foram doados para a comunidade do bairro Pestano com o intuito de se tornarem um instrumento de reivindicação para melhoria urbana e social desses moradores, atuando como promotores da conquista do direito à cidade. Mas mais importante que os projetos são os resultados do processo, como a inserção da comunidade a estes e a elevação da autoestima dos moradores e do lugar.

A comprovação do espírito de coletividade, o fortalecimento dos moradores em decorrência do processo de assistência técnica e o projeto como instrumento de luta e reivindicação, foram comprovados com a mobilização dos moradores em prol da comunidade. Antes mesmo da apresentação de doação dos projetos na comunidade, moradoras marcaram uma reunião com a Prefeita Paula Mascarenhas, no programa "A Prefeita Recebe", solicitando a presença das residentes para acompanhá-las nas pautas, sendo estas: a regularização fundiária, a situação do projeto de qualificação física e social e a possibilidade de execução de parte desses projetos, principalmente das áreas coletivas, visto a impossibilidade do financiamento do todo.

Foi colocada em pauta a assistência técnica realizada no Pestano e a possível implantação dos projetos, apresentando quais são esses anteprojetos e convidando a gestão pública para a doação oficial destes. Em decorrência da reunião o secretário da Secretaria de Serviços Urbanos solicitou reunião para entender melhor a proposta do anteprojeto do ecoponto, pedido também interposto pelas moradoras e a prefeita, que então encontra-se em negociação para futura implantação. 


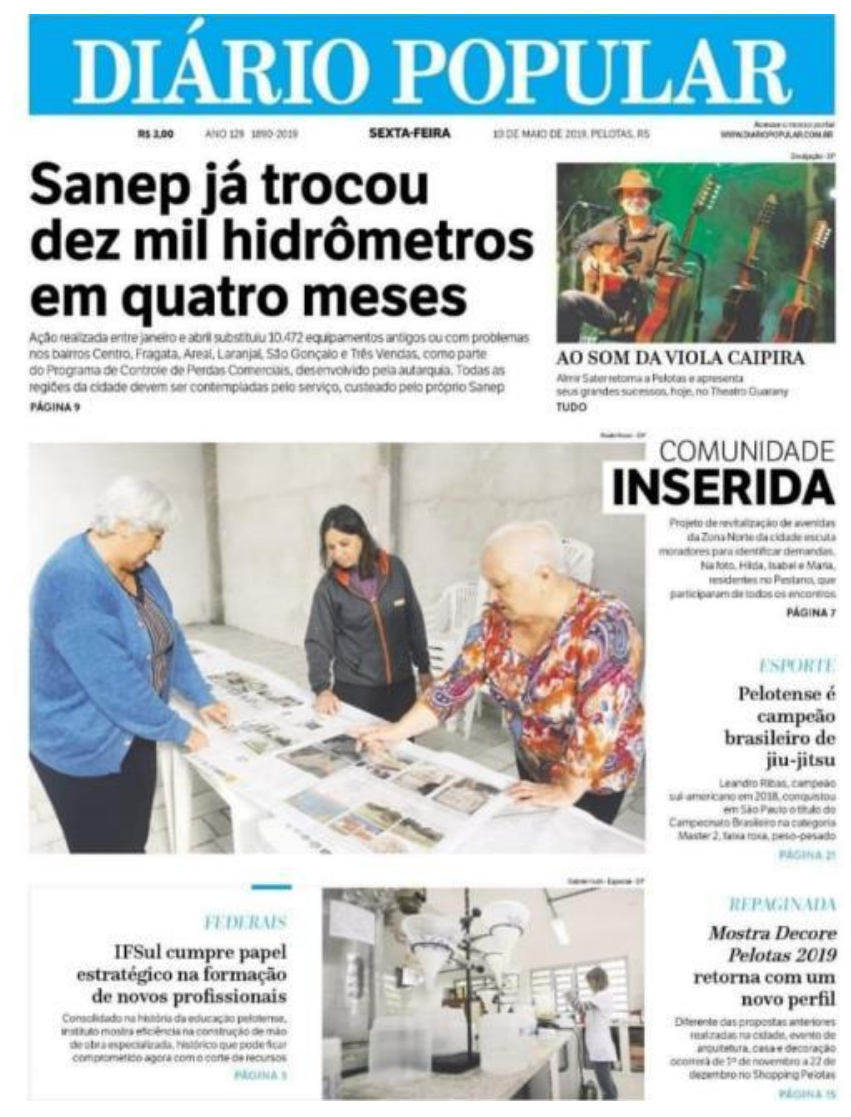

Figura 7 - Foto da capa do jornal Diário Popular, Pelotas - 10/05/2019

Fonte: Jornal Diário Popular (2019)

Além dessas tratativas, o jornal local (Figura 07), estampa a matéria sobre 0 processo, apresentando a importância do mesmo, conforme relatado pela jornalista. "A frase "Eu amo o Pestano" tornou-se símbolo de representação da comunidade e aumento da autoestima dos moradores depois das oficinas voltadas à construção de uma identidade." (MÜLHER, Júlia, 2019).

\section{REFERÊNCIAS}

CARRASCO, A.O.T. O processo de produção do espaço urbano na cidade de pelotas: subsídios para uma reflexão sobre o desenvolvimento das relações de desigualdade entre centro e periferia. Campinas: oculum ensaios, 14(3), p. 595 $-611.2017$.

ROCHA, H. F. M. e MOURA, M. S. Metodologias integrativas em projetos de assistência técnica para comunidades urbanas. Salvador: Revista interdisciplinar de gestão social. Jan/abr. 2016, v. 5, n.1, pp 153-166. 2016 LEFEVBRE, HENRI. O Direito à Cidade. Ed. Centauro. $5^{\circ}$ edição. 2008. MARICATO, Ermínia. Metrópole na periferia do capitalismo. São Paulo: Hucitec. 1996.

MEDVEDOSVSKI. N. S. Diagnóstico rápido urbano participativo (DRUP): um relato sobre a ferramento como instrumento para processos participativos em habitação de interesse social - uma ação extensionista. Pelotas. Expressa Extensão. V. 20 , N 2. 2015. 
BRASIL. Constituição da República Federativa do Brasil de 1988. Disponível em: < http://www.planalto.gov.br/ccivil_03/constituicao/constituicao.htm>. Acesso em: 05.jan.2018.

BRASIL. Lei $\mathbf{n}^{\circ} \mathbf{1 1 . 8 8 8}$, de 24 de maio de dezembro de 2008. Assegura às famílias de baixa renda assistência técnica pública e gratuita para o projeto e a construção de habitação de interesse social e altera a Lei no 11.124, de 16 de junho de 2005. Disponível em:

< https://presrepublica.jusbrasil.com.br/legislacao/92610/lei-1 1888-08> Acesso em: 05.jan.2018.

IBGE. Instituto Brasileiro de Geografia e Pesquisa. Disponível em: <https://www.ibge.gov.br/>. Acesso em: 06.set. 2018.

MÜLLER. Júlia. O projeto de um novo Pestano. Jornal Diário Popular, Pelotas/RS, 10 mai. 2019. Cidades, pag. 7. Disponível em:

<https://www.diariopopular.com.br/geral/o-projeto-de-um-novo-pestano-

141048/? >. Acesso em: 06. junho.2019. 